\title{
Clinical and imaging characteristics of orbital metastatic lesions among Egyptian patients
}

\author{
This article was published in the following Dove Press journal: \\ Clinical Ophthalmology \\ 10 September 2015 \\ Number of times this article has been viewed
}

\author{
Mohammed A Eldesouky \\ Molham A Elbakary \\ Oculoplastic Unit, Faculty of Medicine, \\ Tanta University, Tanta, Egypt
}

Purpose: The aim of the study was to review the demographic, clinical, and imaging features of Egyptian patients with orbital metastases.

Methods: The study was a retrospective study of patients with orbital metastatic lesions over the last 15 years.

Results: The study included 37 patients. Male patients represented $54.1 \%$. The primary tumor was breast carcinoma in $21.6 \%$ of patients, with hepatocellular carcinoma (HCC) in $16.2 \%$ and cutaneous malignant melanoma in $13.5 \%$ of patients. Bronchogenic carcinoma, prostatic carcinoma, and thyroid adenocarcinoma was the primary tumor in $8.1 \%$ of cases each. The most common primary tumor in children was neuroblastoma ( $42.9 \%$ of pediatric patients). In $24.3 \%$ of patients, there was no history of cancer, and the orbital metastatic lesion was the first presentation of the disease. Proptosis and/or globe displacement was the presenting feature in $78.4 \%$, followed by diplopia and limited ocular movements in $35.1 \%$, inflammatory manifestations in $10.8 \%$, and ptosis in $5.4 \%$. In $54.1 \%$ the lesion involved the right orbit and in $5.4 \%$ bilateral involvement was found. Orbital imaging showed infiltrative lesion in $62.2 \%$, mass lesion in $21.6 \%$, isolated muscle thickening in $10.8 \%$, and bone metastasis in $5.4 \%$. All cases of HCC showed osteoclastic changes, and all cases of prostatic carcinoma were osteoblastic lesions.

Conclusion: Orbital metastasis from HCC represented a higher incidence when compared to previous studies, probably due to the increased incidence of HCC found in the Egyptian population. Orbital metastasis can display a variety of clinical and imaging features, and a high index of suspicion is required, as $24.3 \%$ showed negative history of cancer.

Keywords: orbital metastasis, orbital tumors, clinical features

\section{Introduction}

Orbital metastasis can be defined as a metastatic lesion that occurs in the space between the eyeball and bony orbital walls. ${ }^{1}$ The orbit is an unusual site for metastatic cancer. It is believed to occur in approximately $2 \%-3 \%$ of patients with systemic cancer. ${ }^{2,3}$ The incidence of orbital metastatic lesions varied from $1 \%$ to $13 \%$ of orbital tumors. This incidence has been noticed to be increasing in recent years. ${ }^{4}$

Most ophthalmologists and oncologists have had little experience with orbital metastasis. Few studies with considerable numbers of patients have reported the clinical and imaging characteristics of this rare condition in different geographic regions. ${ }^{5-11}$ In this paper, we report the features of orbital metastatic lesions among patients in the Delta region of Egypt over the last 15 years.

\section{Patients and methods}

This was a retrospective study which included all patients who were histologically proven to have orbital metastatic lesions at Tanta University Eye Hospital over the last 15 years (2000-2014). The study adhered to the principles of the Declaration of Helsinki and 
has been approved by Tanta Faculty of Medicine Ethical committee. The medical records of these patients were reviewed for patients' age, sex, history of cancer, primary tumor site, presenting symptoms, and clinical signs. They were also reviewed for imaging criteria including tumor location and laterality, size, configuration, and bone changes. The clinical and imaging data were collected and statistically analyzed.

\section{Results}

The study included 37 patients who were diagnosed through incision biopsy and histologically proven to have orbital metastatic lesions. The patients' ages ranged between 1 and 73 years. The median age was 51 years. The study included seven children. The mean age (mean $\pm \mathrm{SD}$ ) of adult patients in the study was $54.9 \pm 10.1$ years, and the mean age of children was $4.6 \pm 5.4$ years. Twenty patients $(54.1 \%)$ were male and 17 (45.9\%) were female. Breast carcinoma represented $21.6 \%$ of cases (eight patients), followed by hepatocellular carcinoma (HCC), which represented $16.2 \%$ (six patients). These two types of metastatic lesions represented $26.7 \%$ and $20.0 \%$ of adult patients, respectively. The next common primary tumor site was cutaneous malignant melanoma, which accounted for $13.5 \%$ of patients (five cases), followed by bronchogenic carcinoma, prostatic carcinoma, and thyroid adenocarcinoma, each of which accounted for $8.1 \%$ of patients (three cases of each type). The most common primary tumor in pediatric patients was neuroblastoma, with three cases $(42.9 \%$ of pediatric patients and $8.1 \%$ of study patients).

Nine patients $(24.3 \%)$ were not known to be cancer patients, and the orbital lesion was the first presentation of the disease. Three of these patients $(33.3 \%)$ were proven to have HCC. These three patients represented $50 \%$ of the patients in the HCC metastatic lesions category. On the other hand, $87.5 \%$ of patients with breast carcinoma (seven cases) gave a history of their primary tumor (Table 1).

In 20 cases $(54.1 \%)$ the right orbit was involved, while the left orbit was involved in 15 cases $(40.5 \%)$. Two cases had bilateral involvement (5.4\%); one of these was a breast carcinoma case while the other was a neuroblastoma case. The clinical features and presenting symptoms varied between proptosis and/or globe displacement in 29 patients (78.4\%), diplopia and limited ocular motility in 13 patients $(35.1 \%)$, inflammatory manifestations (lid edema and conjunctival chemosis and injection) in four patients (10.8\%), ptosis in two cases (5.4\%), visual loss in two cases (5.4\%), and enophthalmos in one case (2.7\%) (Table 2).

The imaging studies (computed tomography [CT], magnetic resonance imaging [MRI], or both) showed infiltrative lesions in 23 patients $(62.2 \%)$, which were most commonly detected among breast carcinoma (seven cases). Mass lesion was found in eight patients (21.6\%). In four patients (10.8\%), the lesion was detected as an isolated muscle thickening; all of them were malignant melanoma. In two patients (5.4\%) the lesion was in the form of bone metastasis. The two patients had prostatic carcinoma (Table 2, Figure 1). Bone changes were detected in 15 patients $(40.5 \%)$. In eleven cases $(73.3 \%)$, osteoclastic lesions with variable degrees of bone destruction were found. The osteoclastic lesions were found among all patients with HCC (six cases). While in four cases (26.7\%) osteoblastic lesions were detected, three of which were found among patients with prostatic carcinoma (Figure 2).

As regards lesion site, $54.1 \%$ (20 cases) were extraconal, $18.9 \%$ (seven cases) were extra- and intraconal, and 10.8\% (four cases) were intraconal. In six cases the lesions were found as muscle thickening or bone lesions and could not be classified as intraconal or extraconal.

\section{Discussion}

The first case of orbital metastasis was described by Horner in 1864, when he reported a case of a lung cancer metastasis to the orbit. ${ }^{4}$ Since then multiple cases of orbital metastasis have been described in the literature. A metastasis to the orbit is rare and occurs less frequently than a uveal metastasis. ${ }^{4,12}$ The reported incidence of orbital metastatic lesions has been

Table I Types of primary tumors and patients' demographic data

\begin{tabular}{llllll}
\hline Primary tumor & Patients, $\mathbf{n}(\%)$ & Males, $\mathbf{n}$ & Females, $\mathbf{n}$ & Mean age, years & Known cancer patients, $\mathbf{n}(\%)$ \\
\hline Breast carcinoma & $8(21.6)$ & 0 & 8 & 51.6 & $7(87.5)$ \\
Hepatocellular carcinoma & $6(16.2)$ & 6 & 0 & 60.2 & $3(50.0)$ \\
Malignant melanoma & $5(13.5)$ & 2 & 3 & 44.2 & $3(60.0)$ \\
Bronchogenic carcinoma & $3(8.1)$ & 2 & 1 & 53.7 & $2(66.7)$ \\
Prostatic carcinoma & $3(8.1)$ & 3 & 0 & 67.7 & $2(66.7)$ \\
Thyroid adenocarcinoma & $3(8.1)$ & 1 & 2 & 59.3 & $2(66.7)$ \\
Renal cell carcinoma & $2(5.4)$ & 2 & 0 & 55.5 & $2(100.0)$ \\
Neuroblastoma & $3(8.1)$ & 2 & 1 & 1.5 & $3(100.0)$ \\
Leukemia & $2(5.4)$ & 0 & 2 & 10.5 & $2(100.0)$ \\
Ewing sarcoma & $2(5.4)$ & 2 & 0 & 3.5 & $2(100.0)$ \\
\hline
\end{tabular}


Table 2 Clinical and imaging characteristics of orbital metastatic lesions

\begin{tabular}{|c|c|c|c|}
\hline Presenting symptom/sign & Patients, n (\%) & Form of lesion in CT and/or MRI & Patients, n (\%) \\
\hline Proptosis and/or globe displacement & $29(78.4)$ & Infiltrative lesion & $23(62.2)$ \\
\hline Diplopia and/or limited ocular motility & $13(35.1)$ & Mass & $8(21.6)$ \\
\hline Pain & $6(16.2)$ & Isolated muscle thickening & $4(10.8)$ \\
\hline Inflammatory manifestations & $4(10.8)$ & Bone metastasis & $2(5.4)$ \\
\hline Ptosis & $2(5.4)$ & & \\
\hline Enophthalmos & I (2.7) & & \\
\hline
\end{tabular}

Abbreviations: $\mathrm{CT}$, computed tomography; MRI, magnetic resonance imaging.

increasing. A number of factors may account for this increase: the improved treatment has led to an increase in the median survival of cancer patients, which in turn has increased the chances for development of metastatic lesions in unusual sites such as the orbit; advances in the diagnosis and application of serological and molecular diagnostic imaging techniques have led to the increased detection of such lesions; and an increased volume of medical literature on orbital metastasis has increased the awareness of these lesions. ${ }^{6,13,14}$ The actual incidence of orbital metastasis is believed to be higher than that described in the literature. Underestimation of the true incidence can be attributed to several factors. Patients who have small orbital lesions may remain asymptomatic, and general debility in patients with widespread disease may mask the orbital symptoms leading to a low rate of referral to ophthalmologists. ${ }^{4,15}$

Several authors have reported their experience with orbital metastasis. Breast carcinoma has been reported as the commonest primary tumor site with variable incidences. ${ }^{5-11}$ This was also noticed in this study, in which orbital metastasis from breast carcinoma represented $21.6 \%$ of all patients and $26.7 \%$ of adult patients. The second most common primary cancer reported in the literature varies in different series. Shields et $\mathrm{al}^{9}$ published the largest study on orbital metastasis which included
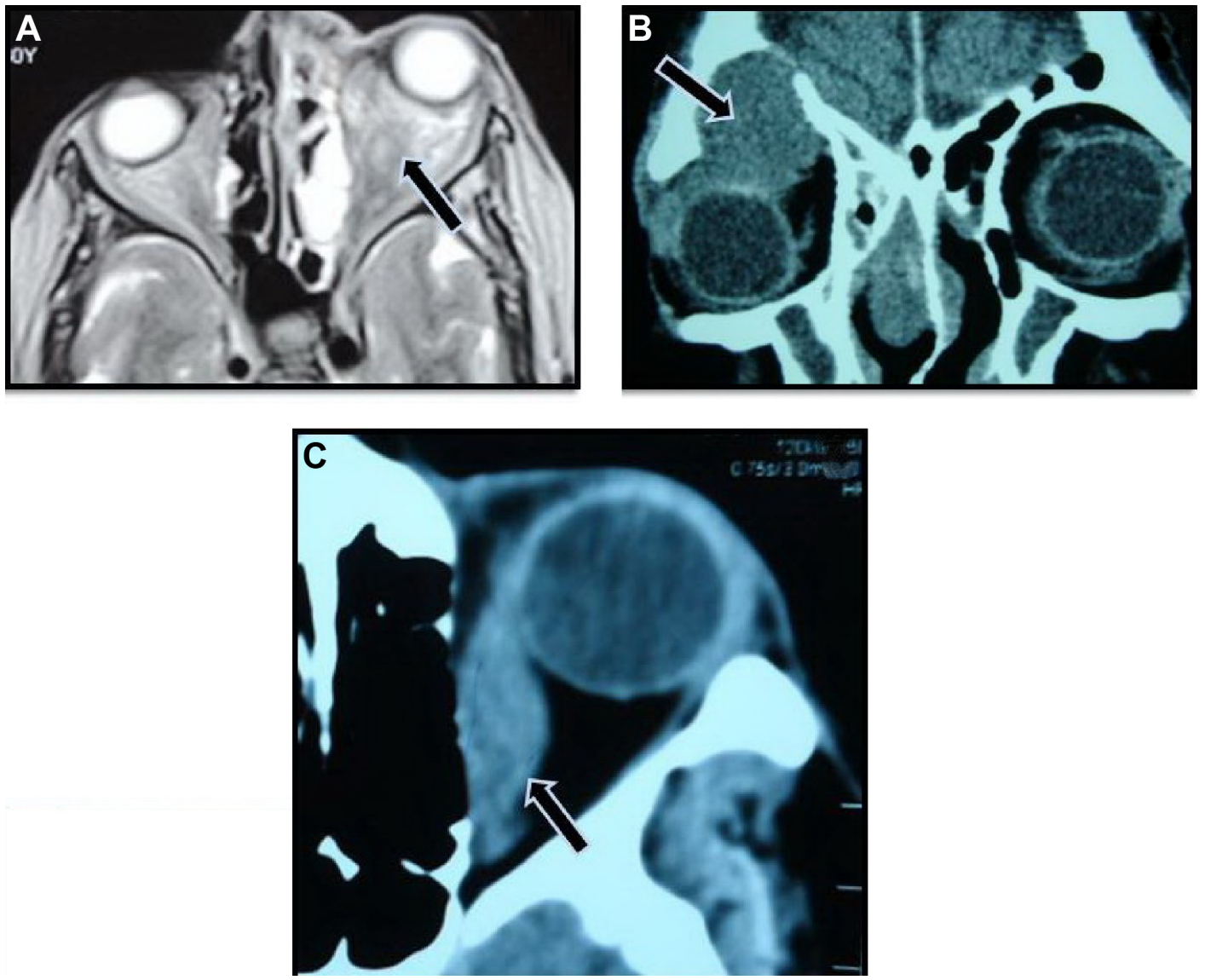

Figure I Imaging patterns of orbital metastasis.

Notes: (A) Magnetic resonance image showing right infiltrative metastatic lesion from breast carcinoma (arrow). (B) Computed tomography (CT) scan with contrast showing well-defined right superior orbital metastatic mass from thyroid carcinoma (arrow). (C) CT scan with contrast showing right isolated medial rectus thickening in a case of orbital metastasis from cutaneous malignant melanoma (arrow). 

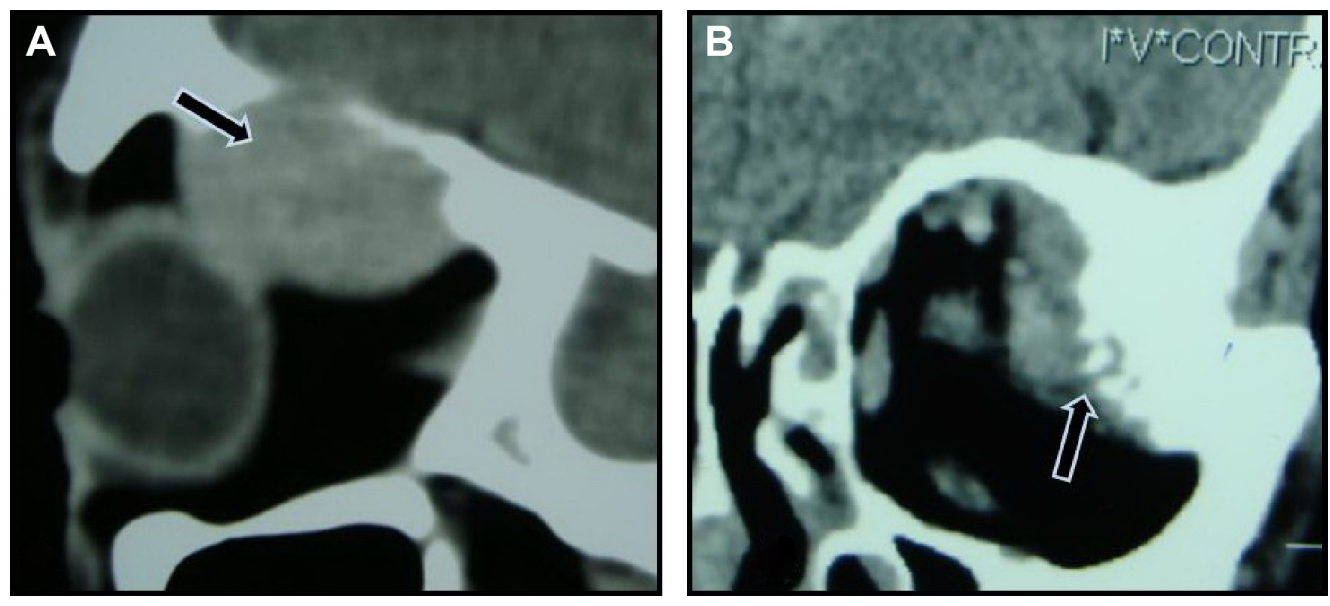

Figure 2 Computed tomography scans with contrast showing bone changes in orbital metastasis.

Notes: (A) Osteoclastic metastatic lesion from hepatocellular carcinoma (arrow). (B) Osteoblastic metastatic lesion from prostatic carcinoma (arrow).

100 patients. They reported prostate cancer as the second most common primary cancer $(12 \%)$ followed by lung cancer $(8 \%)$ and malignant melanoma $(6 \%)$, which was also reported by other authors. ${ }^{5,7}$ Henderson et $\mathrm{al}^{8}$ found bronchogenic carcinoma as the second most common tumor metastasizing to the orbit, while Goldberg et $\mathrm{al}^{6}$ reported skin malignant melanoma as the second most common primary tumor. In a study done in Australia, malignant melanoma was the second primary tumor (20\%) followed by prostatic carcinoma $(13 \%),{ }^{10}$ while in another study done in the People's Republic of China, the most common primary cancer that metastasized to the orbit was nasopharyngeal carcinoma $(30.3 \%)$, followed by lung cancer $(8.7 \%)$, liver cancer $(6.5 \%)$, and breast carcinoma was the fourth $(4.35 \%) .{ }^{11}$ These variations may be related to the different geographic areas of these different studies. The actual incidence of primary tumors metastasizing to the orbit is difficult to ascertain in a clinical series compared to autopsy series. For example, patients with bronchogenic carcinoma are usually markedly affected by their disease by the time an orbital metastasis has occurred. These patients can therefore be underrepresented in comparison with patients of breast cancer, who show a much slower disease course and may stay mobile and healthy enough to get an eye examination. ${ }^{16}$

In this study, $\mathrm{HCC}$ was found to be the second primary tumor site $(16.2 \%)$ followed by cutaneous malignant melanoma (13.5\%). This high incidence of orbital metastasis from $\mathrm{HCC}$ can be attributed to the rising incidence of $\mathrm{HCC}$ in Egypt. The incidence of HCC noticeably increased from approximately $4.0 \%$ in 1993 to $7.3 \%$ in $2003 .{ }^{17}$ The rate of $\mathrm{HCC}$ in Gharbiah (the province in which the study reported here was done) was found to be 3.5 times higher than that reported in the USA. ${ }^{18}$ It is known that chronic hepatitis $\mathrm{C}$ viral infection can lead to liver cirrhosis and
HCC. Africa is reported to have the highest World Health Organization-estimated regional hepatitis $\mathrm{C}$ virus (HCV) prevalence (5.3\%), and Egypt has the highest prevalence of $\mathrm{HCV}$ in the world $(17.5 \%) .^{19-21}$

Diagnosis of orbital metastasis is a challenging task. Kuo et al noted that a cancer patient is a candidate for metastasis for the rest of their life. ${ }^{22}$ In $19 \%-25 \%$ of cases, there may be no history of cancer, and thus the ophthalmologist may play a crucial role in the detection and staging of a previously unsuspected primary cancer. ${ }^{6,14}$ In this study, 24.3\% were not known to be cancer patients. One-third of these patients were found to have $\mathrm{HCC}$, which represented $50 \%$ of the cases with HCC in the study. Even known cancer patients may not give a history of cancer for various reasons including denial, embarrassment, or forgetfulness. Cancer may also be omitted from the history because patients may not think it is relevant to their ocular condition. ${ }^{6}$

Goldberg and Rootman classified the features of orbital metastasis into four categories: infiltrative with prominent motility restriction and sometimes enophthalmos; mass effect with proptosis and/or globe displacement; inflammatory, in which pain, chemosis, and erythema are experienced; and functional, in which there are cranial nerve findings that are out of proportion to the degree of orbital involvement. They reported that the infiltrative lesion is most common although mixed presentations exist as well. ${ }^{6,23}$ We found that proptosis and/or globe displacement was the most common feature, found in $78.4 \%$, followed by motility restriction, which was found in $35.1 \%$.

Orbital imaging using CT and MRI are the principal means of evaluating orbital lesions. CT may be more beneficial in patients with prostatic carcinoma which has a tendency to metastasize to bone with development of osteoblastic orbital lesions. ${ }^{4,14}$ Osteoclastic lesions can be found 
in metastasis from $\mathrm{HCC}$ which varies from bone notching and thinning to bone erosion. ${ }^{24}$ Orbital metastatic lesions can be extraconal or intraconal. They may range from a diffuse infiltrative pattern to a focal lesion. Enlargement of one or more of the extraocular muscles may be found in patients with metastatic cutaneous melanoma. ${ }^{4,25}$

The definitive diagnosis of an orbital metastasis requires tissue diagnosis. Fine needle aspiration biopsy has been advocated as a good diagnostic modality. ${ }^{26}$ There have, however, been reports of dissemination of tumor cells with the procedure, and there is a risk of globe injury, although the likelihood of these complications is low. ${ }^{6,26,27}$ Incision biopsy of accessible lesion is a good diagnostic option, but in patients showing widespread metastatic disease and in who the diagnosis of cancer is established, an orbital biopsy may not be necessary and its inherent risks can be avoided as the diagnosis can be established on the basis of other findings. ${ }^{4}$

\section{Conclusion}

Orbital metastasis can display a wide variety of clinical and imaging features. A high index of suspicion is required, as $24.3 \%$ did not have history of cancer in our study and orbital lesion was the first manifestation of the disease. A high incidence of orbital metastasis from HCC was found, which, as far as we are aware, has not been reported by any previous study; this can be explained on the basis of the increased incidence of HCC in the Egyptian population.

\section{Disclosure}

The authors report no conflicts of interest in this work.

\section{References}

1. Finger PT. Radiation therapy for orbital tumors: concepts, current use, and ophthalmic radiation side effects. Surv Ophthalmol. 2009;54(5): 545-568.

2. Albert DM, Rubenstein RA, Scheie HG. Tumor metastasis to the eye. I. Incidence in 213 adult patients with generalized malignancy. Am J Ophthalmol. 1967;63(4):727-732.

3. Bloch RS, Gartner S. The incidence of ocular metastatic carcinoma. Arch Ophthalmol. 1971;85(6):673-675.

4. Ahmad SM, Esmaeli B. Metastatic tumors of the orbit and ocular adnexa. Curr Opin Ophthalmol. 2007;18(5):405-413.

5. Shields CL, Shields JA, Peggs M. Tumors metastatic to the orbit. Ophthal Plast Reconstr Surg. 1988;4(2):73-80.

Clinical Ophthalmology

\section{Publish your work in this journal}

Clinical Ophthalmology is an international, peer-reviewed journal covering all subspecialties within ophthalmology. Key topics include: Optometry; Visual science; Pharmacology and drug therapy in eye diseases; Basic Sciences; Primary and Secondary eye care; Patient Safety and Quality of Care Improvements. This journal is indexed on Submit your manuscript here: http://www.dovepress.com/clinical-ophthalmology-journal
6. Goldberg RA, Rootman J, Cline RA. Tumors metastatic to the orbit: a changing picture. Surv Ophthalmol. 1990;35(1):1-24.

7. Tijl J, Koornneef L, Eijpe A, Thomas L, Gonzalez DG, Veenhof C. Metastatic tumors to the orbit - management and prognosis. Graefes Arch Clin Exp Ophthalmol. 1992;230(6):527-530.

8. Henderson JW, Campbell RJ, Farrow GM, et al. Metastatic carcinomas. In: Henderson JW. Orbital Tumors. 3rd ed. New York, NY: Raven Press; 1994:361-376.

9. Shields JA, Shields CL, Brotman HK, Carvalho C, Perez N, Eagle RC Jr. Cancer metastatic to the orbit: the 2000 Robert M. Curts Lecture. Ophthal Plast Reconstr Surg. 2001;5:346-354.

10. Valenzuela AA, Archibald CW, Fleming B, et al. Orbital metastasis: clinical features, management and outcome. Orbit. 2009;28(2-3):153-159.

11. Yan J, Gao S. Metastatic orbital tumors in southern China during an 18-year period. Graefes Arch Clin Exp Ophthalmol. 2011;249(9):1387-1393.

12. Shields CL, Shields JA, Gross N, Schwartz GP, Lally SE. Survey of 520 uveal metastases. Ophthalmology. 1997;104(8):1265-1276.

13. Char DH, Miller T, Kroll S. Orbital metastasis: diagnosis and course. Br J Ophthalmol. 1997;81(5):386-390.

14. Garrity JA, Henderson JW, Cameron JD. Metastatic carcinomas. In: Henderson's Orbital Tumors. 4th ed. New York, NY: Raven Press; 2007: 313-326.

15. Fenton S, Kemp SE, Harnett AN. Screening for ophthalmic involvement in asymptomatic patients with metastatic breast carcinoma. Eye (Lond). 2004;18(1):38-40.

16. Katz S, Rootman J, Goldberg R. Secondary and metastatic tumors of the orbit. In: Duane's Ophthalmology. Philadelphia, PA: Lippincott Williams \& Wilkins; 2007.

17. el-Zayadi AR, Badran HM, Barakat EM, et al. Hepatocellular carcinoma in Egypt: a single center study over a decade. World J Gastroenterol. 2005;11(33):5193-5198.

18. Lehman EM, Soliman AS, Ismail K, et al. Patterns of hepatocellular carcinoma incidence in Egypt from a population-based cancer registry. Hepatol Res. 2008;38(5):465-473.

19. Yeh MM, Daniel HD, Torbenson M. Hepatitis C-associated hepatocellular carcinomas in non-cirrhotic livers. Mod Pathol. 2010;23(2):276-283.

20. Karoney MJ, Siika AM. Hepatitis C virus (HCV) infection in Africa: a review. Pan Afr Med J. 2013;14:44.

21. Lehman EM, Wilson ML. Epidemic hepatitis C virus infection in Egypt: estimates of past incidence and future morbidity and mortality. $J$ Viral Hepat. 2009;16(9):650-658.

22. Kuo SC, Hsiao SC, Chiou CC, Chen FF, Huang KC. Metastatic carcinoma of the breast: a case with the unusual presentation of unilateral periorbital edema. Jpn J Ophthalmol. 2008;52(4):305-307.

23. Goldberg R, Rootman J. Clinical characteristics of metastatic orbital tumors. Ophthalmology. 1990;97(5):620-624.

24. Eldesouky MA, Elbakary MA, Shalaby OE, Shareef MM. Orbital metastasis from hepatocellular carcinoma: report of 6 cases. Ophthal Plast Reconstr Surg. 2014;30(4):e78-e82.

25. Zografos L, Ducrey N, Beati D, et al. Metastatic melanoma in the eye and orbit. Ophthalmology. 2003;110(11):2245-2256.

26. Kennerdell JS, Dekker A, Johnson SL, Dubois PJ. Fine needle aspiration biopsy: its use in orbital tumors. Arch Ophthalmol. 1979; 97(7):1315-1317.

27. Liu D. Complications of fine needle aspiration biopsy of the orbit. Ophthalmology. 1985;92(12):1768-1771.

\section{Dovepress}

PubMed Central and CAS, and is the official journal of The Society of Clinical Ophthalmology (SCO). The manuscript management system is completely online and includes a very quick and fair peer-review system, which is all easy to use. Visit http://www.dovepress.com/ testimonials.php to read real quotes from published authors. 